\title{
Renewable energy scenarios in the portuguese electricity system
}

\author{
Liliana Fernandes, Paula Ferreira*
}

University of Minho

Center for Industrial and Technology Management

Campus Azurem

4800-058 Guimaraes PORTUGAL

*Corresponding author: Tel:+351253510670; Fax: +351253510343

Email: paulaf@dps.uminho.pt

\begin{abstract}
Portugal has been demonstrating over the years a high dependence of imported fossil fuels, especially with regard to the transportation and electricity production sectors. The urgent need to balance supply and demand as well as the growing concern about environmental issues and reduction of external energy dependency justified an increasing interest in the exploitation of renewable energy sources (RES) looking for more efficient strategies in terms of economic and social or environmental dimensions. The electricity sector represented a clear example of this RES trend with European and Portuguese policies focused on strategies promoting renewable resources and energy efficiency. Following different studies already conducted in other countries, this paper presents an approach to a possible $100 \%$ renewable electricity scenario in Portugal, supported by the application of the model EnergyPLAN. The importance of the interconnection as stabilization measure for a system highly dependent on renewable energy sources of variable output is put in evidence. The results also established that the cost structure of each scenario is mainly driven by the low marginal cost of renewable technologies along with their high investment costs.
\end{abstract}

KEYWORDS: Renewable energy sources (RES); Portugal; 100\% renewable scenarios

JEL Classification: Q42; C63; P48 


\section{Introduction}

The acknowledgment of the need to take advantage of opportunities which endorse economic growth combined with a sustainable energetic policy, has led to several investments in Renewable Energy Sources (RES), which, in turn, aim to have a positive impact on the local and regional development.

Considering energy as the source of economic growth and sustainable development, it is urgent to witness a shift of paradigm where the RES become more than just an environmental necessity, but are indeed perceived as a strategy for security, development and innovation.

Although Portugal remains as one of the European Union countries with highest energy dependency rate, there is a perceptible growing importance of endogenous energy resources, especially regarding the production of electricity.

As a result of the national and international crisis, Portugal's economy remains inactive, or as some might consider, in contraction. However, forecasts for the sector still foreseen an increase of the electricity consumption for the next years. In order to comply with this, studies such as REN (2011) and DGEG (2012) established that the internal production would strongly rely on the expansion of the hydro and wind installed capacity combined with a special emphasis on the development of solar energy and other RES such as biomass, biogas, geothermal and wave energy.

Within this context, and so as to reduce the dependency on the fossil fuels and optimize the electricity system, several methodologies have come forward, enabling the analysis of future scenarios of generation of electricity through renewable systems. These renewable systems are expected to contribute to sustainable development and the models used for the analysis frequently rely on the computation of costs of electricity generation, $\mathrm{CO}_{2}$ emissions and external costs and benefits (externalities). These studies have been accompanied by informatics tools which assist within the decision-making process, foreseeing scenarios and appointing optimal in each one of the electric system indicators.

This paper proposes the use of the EnergyPLAN one of the best-known models in the energy planning area (Connolly et al., 2011). The model was adapted to the Portuguese case and simulating a $100 \%$ renewable electricity system.

\section{2. $100 \%$ Renewable Models and Scenarios for electricity systems}

Nowadays, it has been witnessed in many World countries, a conscientiousness of the Greenhouse Gas Emission (GHG) and its consequences towards climate, in particular over the past few years. The unpredictability and high costs of fossil fuels, the energetic dependency and 
the environmental hazards derived from the consumption of "traditional" energy sources, have placed the electrical generation system as one of its main contributors.

One of the most effective solutions is the integration of RES, already established in normative documentation. However, the main constraint faced by the production of electricity from RES relates to its "intermittent nature", which can lead to high costs related to storage systems (Cósic, B. et al., 2011).

The possibility combining different RES has been approached by different authors who have analyzed the potential of the generation of electricity systems based on $100 \%$ renewable scenarios (see for example Cósic, B. et al., 2011 or Mathiesen et al., 2011). Krajačić, G., et al. (2011), presented already the application of a computational model for the production of electricity in Portugal in a possible 100\% RES system. The results "demonstrated that the solution preferred 100\% renewable hydropower and wind energy," although the latter should be implemented in combination with "reversible hydroelectric and pumping capacity."

The complexity of the systems under analysis is evident both from the data and from the model effort required. These systems require a simulation of possible future scenarios, through the adoption of planning models based on computing tools. These simulations will enable the flexibility of the processing of data and the time-efficient elaboration of different scenarios which guarantee the possibility to introduce supplementary data, such as seasonality of demand and time variations.

\section{Renewable Scenarios within electricity systems}

\subsection{Assumptions and data}

This paper aims to present renewable scenarios for the generation of electricity in Inland Portugal relying on the EnergyPLAN model. The four scenarios established for the country, are presented below:

1. Scenario 1: reference scenario/model validation, with 2010 as reference year;

2. Scenario 2: alternative scenario for 2020 , according to values presented in the National Action-Plan for Renewable Energies (PNAER) (DGEG, 2012);

3. Scenario 3: scenario for 2022, according to values presented in the Development and Investment Plan of the National Transports Network 2012-2017 (2022) (PDIRT - REN, 2011);

4. Scenario 4: $100 \%$ renewable scenario with total exchange of fossil fuels by renewable energies. 
Whenever necessary, it was introduced the hourly time distribution of electricity supply and demand. In every scenario, a technical analysis of the calculation settings was undertaken, as well as a perspective of costs and associated $\mathrm{CO}_{2}$ emissions.

The EnergyPLAN model is computer-based and aims to analyze the Energy Systems. The main goal of the model is to serve as a tool in the elaboration of national energetic strategies based on technical and economical analysis coming from the implementation of different energy systems and investments (Lund, H., 2011). Being considered as an input/output model, the model simulates a time analysis over a 1 year period. This way, the EnergyPLAN enables the optimization of the energy systems based in the technical management of its components, foreseeing the reduction of the imposed financial restraints in the established scenarios, in particular, when considering future perspectives of alternative solutions (Connolly, D., et al., 2011).

The technical data included in Scenario 1 were based on public data from REN. Therefore in 2010 , concerning electric consumption, Portugal presented a total of $52.3 \mathrm{TWh} /$ year and a total balance imports/export balance of -2.6 TWh/year. Thermo-power plants accounted for 7407 MW and RES power plants accounted for $8404 \mathrm{MW}$. Cogeneration and the transmission capacity of the system were also accounted for with this last one achieving $1600 \mathrm{MW}$ (PDIRT REN, 2011). A minimum production stabilization rate equal to 0.3 was assumed, to ensure the stability of the electricity network with dispatching technologies.

Scenario 2 was designed for the year 2020 and figures presented after the revision of the National Action-Plan for the Renewable Energies were assumed, covering the set of goals to be accomplished by 2020 and the respective measures for this purpose, which mainly relies in principles such as reducing energy dependence of the country and aspiring to a sustainable electricity system. It should be underlined that the reduced version of this document does not present enough information for complying with all the necessary parameters for the modeling, however it is indeed the most up-to-date document and it is framed within the current economic outlook. Scenario 3 provides a forecast of the electrical system in Portugal for the year 2022 based on strategies built within the Development and Investment Plan of the National Transports Network. This scenario relies on higher electricity consumption forecasts and also on higher RES shares. The last scenario was designed with the aim of introducing an open system, with outdoor exchanges, targeting $100 \%$ RES to electricity and by this replacing all fossil fuels in the electricity system. Electricity demand projections from scenario 2 were assumed. This scenario favors the installed capacity of wind power (onshore and offshore) which totalizes 9970 MW. Still, in this scenario, it has been considered a sum of installed capacity for wave energy proposed by Krajacić G., et al. (2011). Such introduction was necessary due to the interconnection capacity being limited (3000 MW). Furthermore, decentralized electricity storage systems were not included.

Table 1 summarizes the main data used and additional details on the scenarios can be found in Fernandes (2012). 
Table 1 Main data used for four scenarios under analysis

\begin{tabular}{|c|c|c|c|c|}
\hline & Scenario 1 & Scenario 2 & Scenario 3 & Scenario 4 \\
\hline Electric Consumption (TWh/ year) & 52.3 & 53.6 & 66.43 & 53.6 \\
\hline Imports/ Exports Income (TWh/ year) & -2.6 & -1.9 & -1.9 & -1.9 \\
\hline Coal(TWh/ year) & 6.6 & 2.26 & 6.6 & 0 \\
\hline Fuel (TWh/ year) & 0.047 & 0.014 & 0 & 0 \\
\hline Natural Gas (TWh/ year) & 10.7 & 16.20 & 15.3 & 0 \\
\hline Biomass (TWh/ year) & 1.2 & 2 & 3.1 & 3.1 \\
\hline Thermoelectric plants (installed capacity - MW-e) & 7407 & 6900 & 7245 & 0 \\
\hline Wind (MW) & 3225 & 5300 & 7350 & 9970 \\
\hline Photovoltaic (MW) & 100 & 500 & 1600 & 4500 \\
\hline Run-of-the-river Water (MW) & 2380 & 4750 & 3389 & 3389 \\
\hline Waves (MW) & 0 & 6 & 275 & 3000 \\
\hline Dams (MW-e) & 2117 & 4250 & 6971 & 6971 \\
\hline Dams pumping efficiency (\%) & 100 & 100 & 100 & 100 \\
\hline Dams - average storage capacity (GWh) & 3.076 & 6.152 & 10.151 & 10.151 \\
\hline Dams pumping (MW-e) & 492 & 492 & 5002 & 5002 \\
\hline Dams water supply (TWh/ year) & 6.5 & 13 & 21.4 & 21.40 \\
\hline PRE thermal (TWh/ year) & 7.332 & 8.84 & 9.72 & 0 \\
\hline PRE thermal (fuel) (TWh/year) & 2.866 & 3.33 & 3.24 & 0 \\
\hline PRE thermal (natural gas) (TWh/ year) & 2.866 & 3.33 & 3.24 & 0 \\
\hline PRE thermal (biomass) (TWh/ year) & 1.6 & 2.18 & 3.24 & 3.24 \\
\hline
\end{tabular}

This work also aims to provide a summarized economic analysis of the scenarios. Due to significant differences between the different types of technology used for generating electricity, the used data are compiled in Table 2.

Table 2 Technic and economic data used for the electricity generation technologies

\begin{tabular}{|l|c|c||c|c|c|c|c|}
\hline & $\begin{array}{c}\text { Investment } \\
\text { Costs } \\
(€ / \mathrm{MW})\end{array}$ & $\begin{array}{c}\text { O\&M } \\
(€ / \mathrm{MWh})\end{array}$ & $\begin{array}{c}\text { Life } \\
\text { time }\end{array}$ & $\begin{array}{c}\text { Fuel costs } \\
(€ / \mathrm{MWh})\end{array}$ & $\begin{array}{c}\text { Efficiency } \\
(\%)\end{array}$ & $\begin{array}{c}\mathrm{CO}_{2} \\
\text { (ton/ } \mathbf{M W h})\end{array}$ & $\begin{array}{c}\text { Cost } \\
\mathrm{CO}_{2} \\
(€ / \text { ton })\end{array}$ \\
\hline Coal & 1.646 .820 & 4,65 & 40 & 23,38 & 37,5 & 0,900 & \multirow{2}{*}{15,24} \\
\hline Natural Gas & 825.242 & 3,46 & 30 & 54,43 & 55,9 & 0,370 & \\
\hline
\end{tabular}




\begin{tabular}{|c|c|c|c|c|c|c|c|}
\hline Fuel & - & 2,2 & - & 114,22 & 45,7 & 0,800 & \\
\hline Water - Dam & 1.443 .00 & 8,32 & 50 & 0 & - & 0 & \\
\hline $\begin{array}{l}\text { Run-of-the-river } \\
\text { Water }\end{array}$ & 1.662 .000 & 3,87 & 50 & 0 & - & 0 & \\
\hline $\begin{array}{l}\text { Water - mini } \\
\text { hydro }\end{array}$ & 2.036 .800 & 4,33 & 50 & 0 & - & 0 & \\
\hline Wind & 1.813 .060 & 16,92 & 24 & 0 & - & 0 & \\
\hline Photovoltaic & 4.635 .080 & 23,12 & 25 & 0 & - & 0 & \\
\hline Waves & 5.000 .000 & 30 & 60 & 0 & - & 0 & \\
\hline Biomass & 2.500 .000 & 4 & 20 & 9 & 27,7 & 0,022 & 15,24 \\
\hline $\begin{array}{l}\text { Cogeneration of } \\
\text { Natural Gas }\end{array}$ & 700.000 & 4,5 & 20 & 54,43 & 75 & 0,289 & 15,24 \\
\hline $\begin{array}{l}\text { Cogeneration of } \\
\text { Fuel }\end{array}$ & 1.050 .000 & 9 & 20 & 114,22 & 78 & 0,695 & 15,24 \\
\hline $\begin{array}{l}\text { Cogeneration of } \\
\text { Biomass }\end{array}$ & 800.000 & 3 & 35 & 9 & 75 & 0,022 & 15,24 \\
\hline
\end{tabular}

\subsection{Analysis of the results}

Figure 1 represents the total amount of electricity produced from RES, where the increasing trend is evident. The value obtained for Scenario 4 in fact presents a total amount of electricity production (100\% RES) higher than the expected electricity consumption which has to due to the large amount of RES power present in the system required to avoid electricity shortage in peak moments. However, this leads evidently to excess of production on lower consumption moments. 


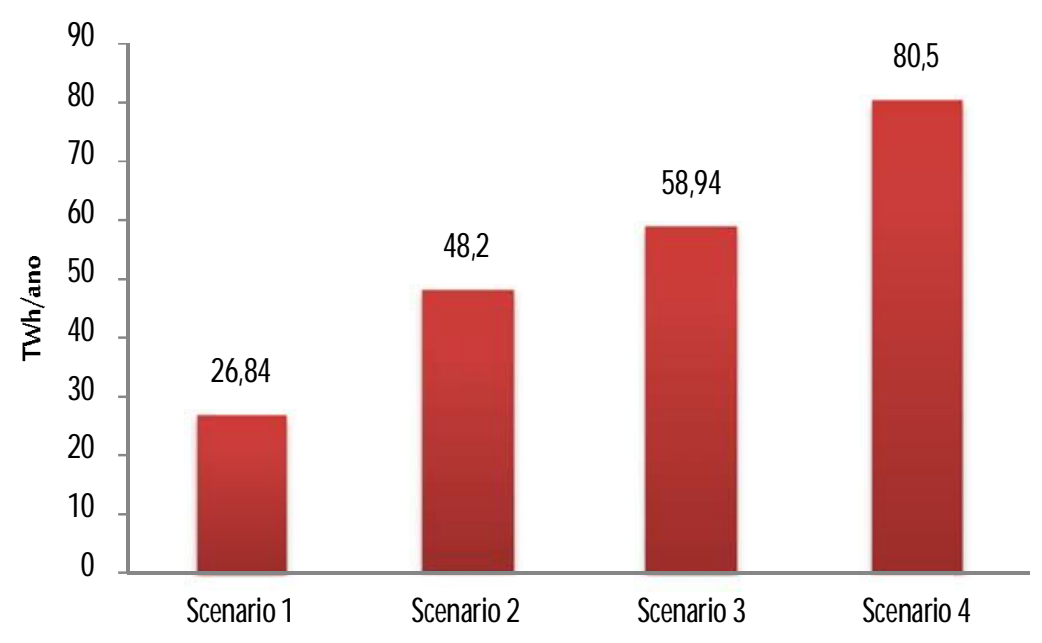

Figure 1 Production of electricity from RES

Due to the large amount of data available to be analyzed two relevant weeks were selected for further detail on the result, corresponding to a winter and a summer week.

In Scenario 1, the recorded values indicate that during winter the increased production for wind and hydro power is reported. The summer figures put in evidence the "dry" season with very low values for hydro power production.. In fact, it is observable that electricity from wind power presents higher values than electric consumption, in some days of the week. However, production coming from photovoltaic and thermal energy sources present higher figures in August. In comparison, during August, the average pumping is practically non-existent and the average values of storage sum $200 \mathrm{MW}$.

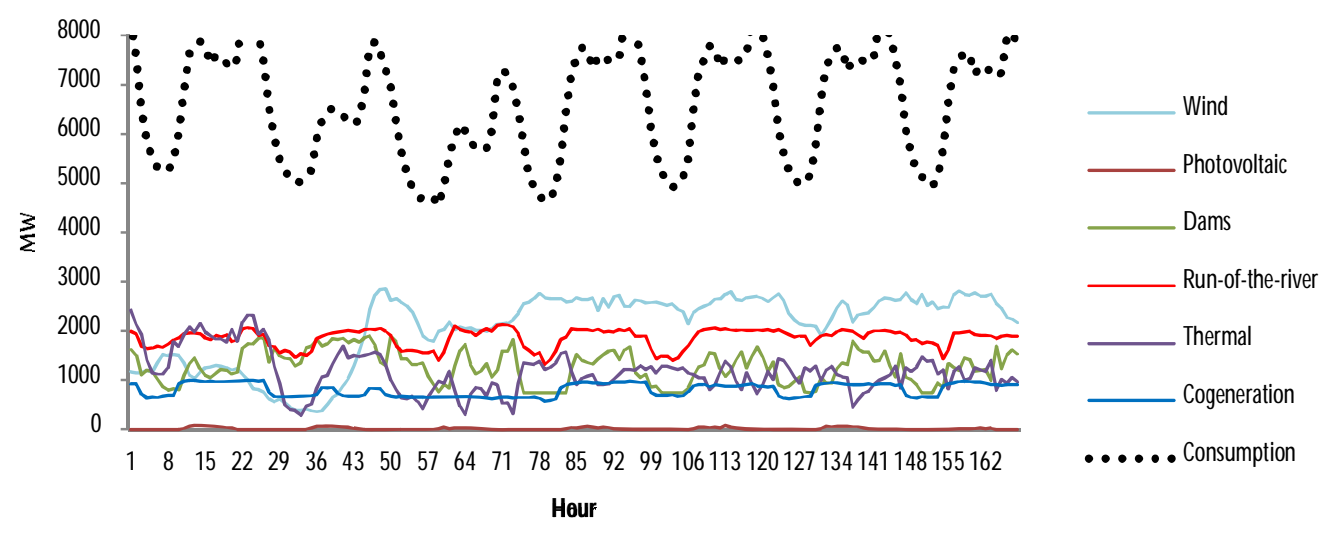

Figure 2 Hourly distribution of consumption and production of electricity in Scenario 1 in February 


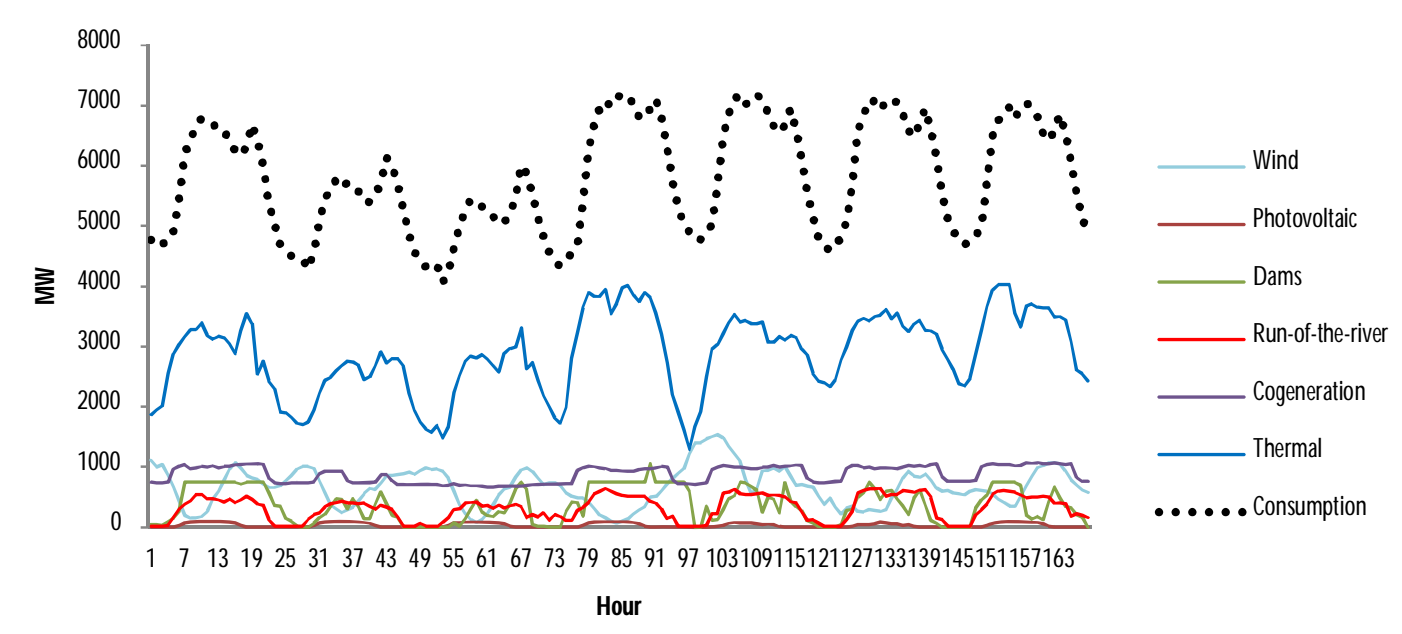

Figure 3 Hourly distribution of consumption and production of electricity in Scenario 1 in August

In Scenario 4, in the winter week, there is still a predominance of wind energy production; however, in this scenario, electricity production from dams is higher than the run-of-the-river water (including mini-hydro). As this is a $100 \%$ RES scenario, the thermal production from fossil fuels is not included.

As it was expected, during summer, photovoltaic energy presents more significant figures when comparatively to the winter week, while hydro and wind production decreased considerably. Moreover, it should be taken into account the fact that during summer the pumping capacity decreases as well as the dam storage values (457 MW on average).

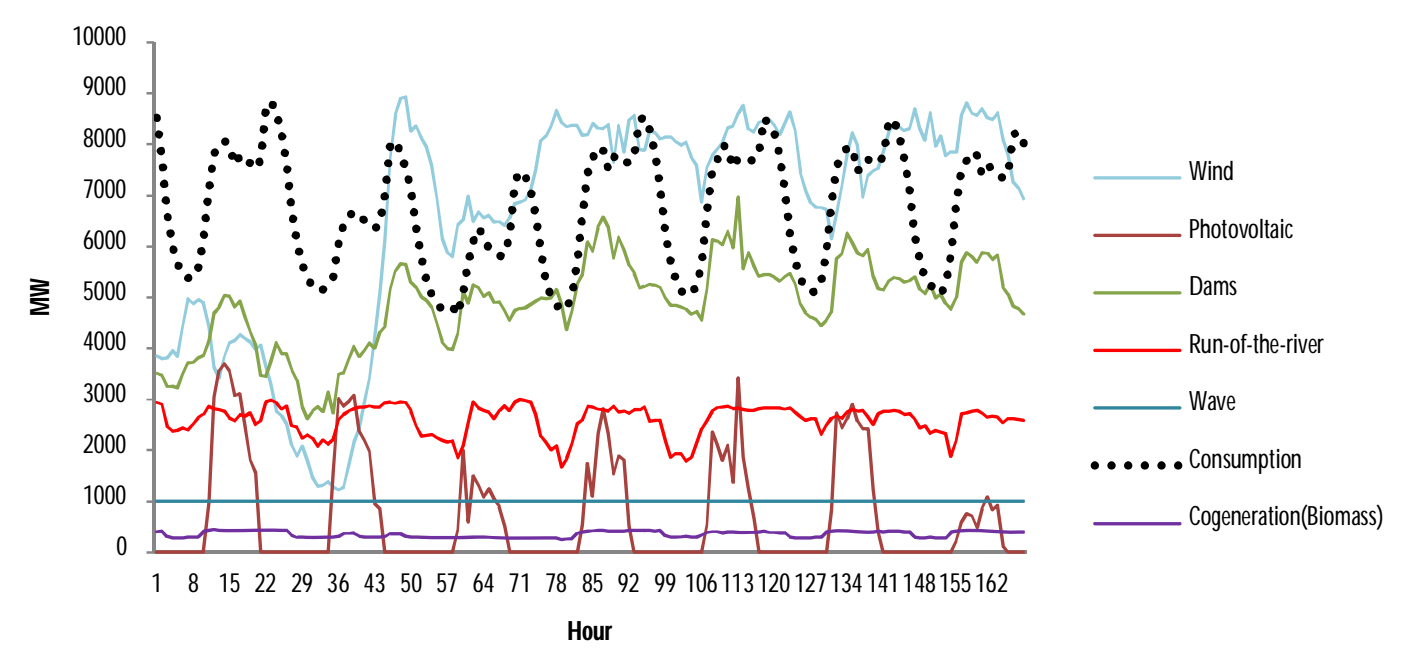

Figure 4 Hourly distribution of consumption and production of electricity in Scenario 4 in February 


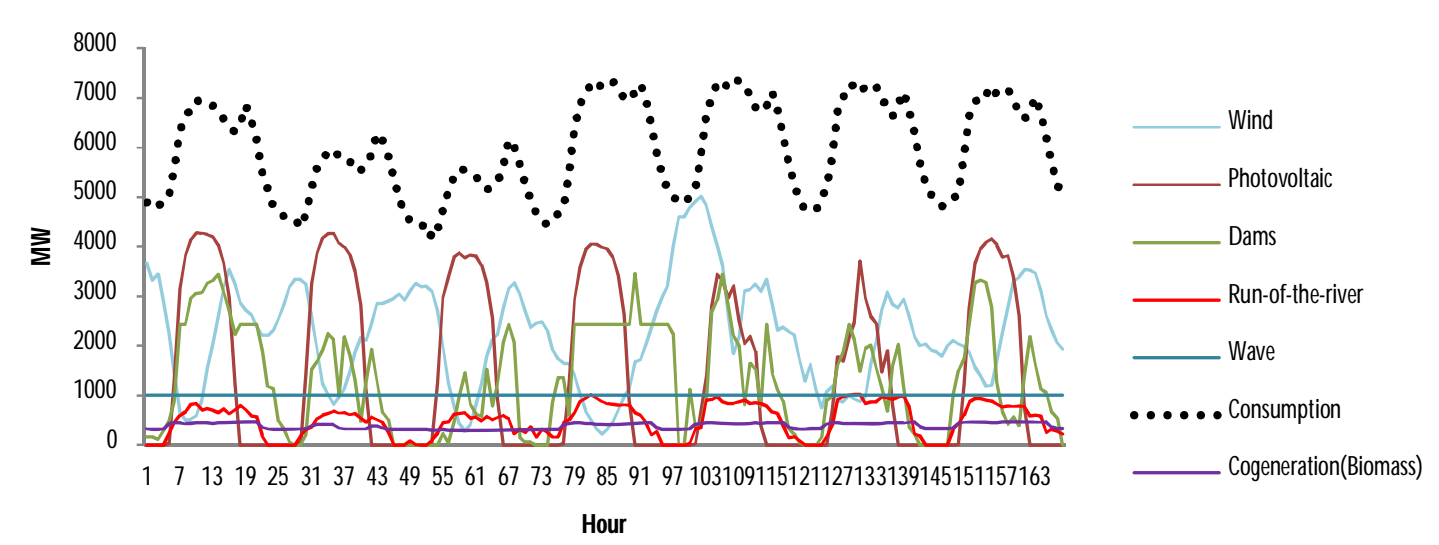

Figure 5 Hourly distribution of consumption and production of electricity in Scenario 4 in August

The EnergyPLAN model allows analyzing results related to electricity production excess throughout the year. This way, the Critical Excess Electricity Production (CEEP) refers to the full amount of energy which is exceeding the electricity needs and the interconnection capacity. As for the Exportable Excess Electricity Production (EEEP), these values relate to the amount of electricity which may be effectively exported.

This work aims to obtain a technical optimization of the electrical balances, therefore assuming open systems to the outside through the introduction of a fixed import/export scale and of a transmission capacity which varies between $1600 \mathrm{M} \mathrm{W}$ and $3000 \mathrm{M} \mathrm{W}$, for all scenarios.

According to Figure 6 (see below), it is possible to recognize that additional imports assume the figure "Zero" in scenarios 1, 2 and 3. Scenario 4 (100\% RES), presents an average import value of $77 \mathrm{MW}$. This scenario provides more significant importation figures during summer, as both wind and hydro production decrease during these months. Meanwhile, exports and consequently the CEEP assume higher annual average figures under Scenarios 2 and 4, which pose as a critical factor when stabilizing the network particularly in the last scenario. These CEEP peaks occur in typical winter months, when both the wind and hydro production increase which would allow exporting electricity if allowed by the interconnection capacity. However, in the typical summer months there is a considerable decrease of the mentioned RES electricity production. Although Scenario 3 assumes a similar transmission capacity, it presents lower CEEP values. These differences are justified by the assumed lower electricity consumption and lower percentage of renewable energy integration for the more conservative Scenario 2. As for the EEEP, all the scenarios have an annual average value above $100 \mathrm{M} \mathrm{W}$. In Scenario 1, the installed transmission interconnection capacity is only $1600 \mathrm{MW}$ which of course leads to lower exportation values, compared to the other three scenarios with interconnection capacity equal to $3000 \mathrm{MW}$. The importance of the importation and exportation balance is demonstrated in Figure 6 for all the four scenarios. 


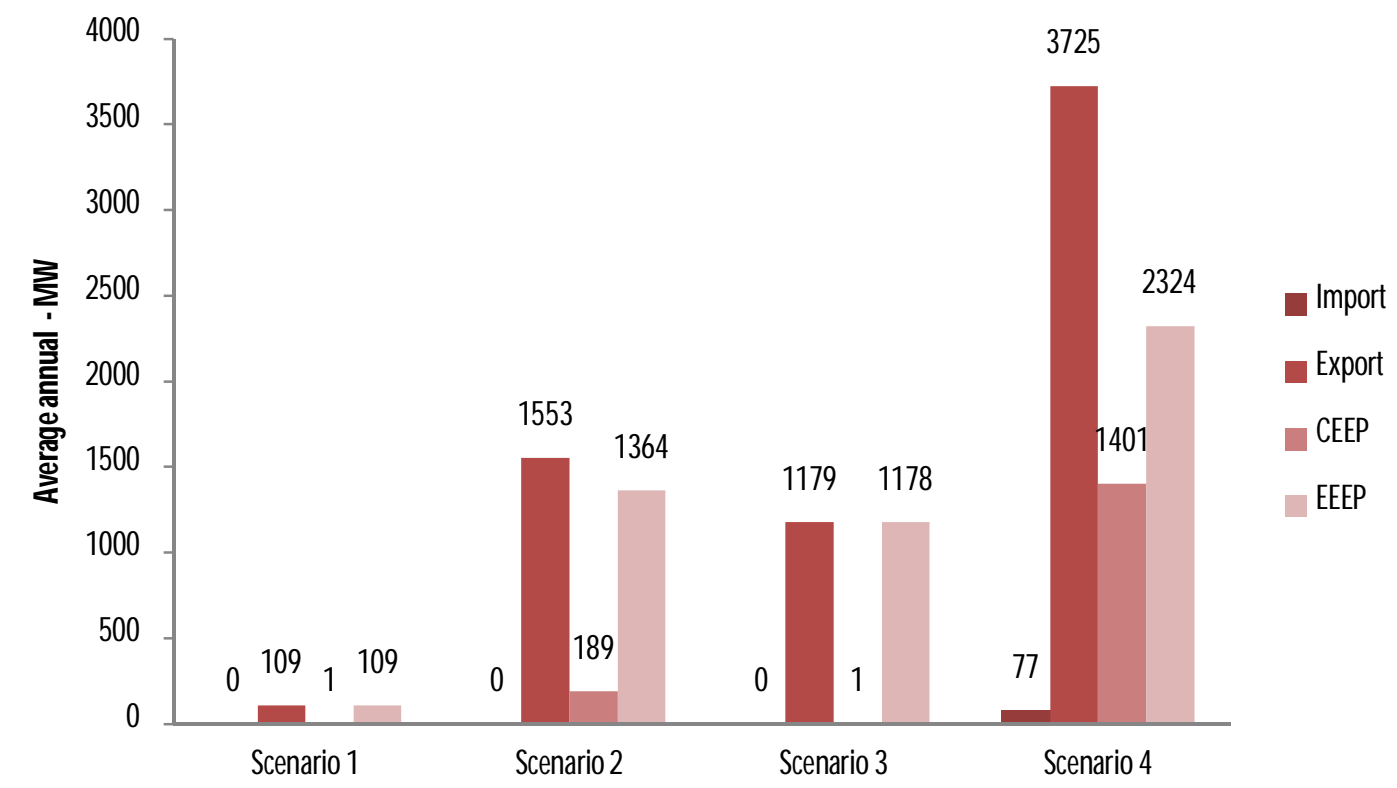

Figure 6 Average annual electricity balances

The computed costs for each one of the Scenarios were based on estimated investment cost for each one of the electricity technology production assuming an incremental approach in relation to the validation scenario (Scenario 1).

The results obtained from the calculation of the marginal costs, including the production costs coming from each technology, the operation and maintenance costs, the fuel costs and the costs with the $\mathrm{CO}_{2}$ emissions have enabled to conclude that, when analyzed independently, they present a gradual reduction from Scenario 1 to Scenario 4. This cost reduction may be explained by a set of different factors. Firstly, it is due to the low operating and maintenance costs of renewable energy power plants when compared to fossil fuels thermal power plants. Secondly, it is due to the avoidance of fuel costs and $\mathrm{CO}_{2}$ emission allowances brought by the increasing share of RES power plants.

Thus, Scenario 1 presents higher figures for marginal costs $(35,13 € / \mathrm{MW})$ due to the presence of thermal and cogeneration power plants, as well as it presents a lower integration of renewable energy when compared with the other three scenarios. In turn, Scenarios 2 and 3 with a higher production of renewable energy present comparatively lower marginal costs (29,33 €/MW and 22,16 €/MW respectively). Scenario 4 presents considerably low figures regarding marginal costs $(14,33 € / \mathrm{MW})$ due to total exchange of fossil fuels for renewable energies. The values of the marginal costs as described in Figure 7. 
However, when the analysis refers to the total cost of each scenario including investment costs on the computation of the average cost of the system in $€ / M W h$ (Figure 8), the situation presents itself in reverse, with higher values in scenarios where it has been designed a greater uptake of renewable energies. This is due to the fact that the investments cost of RES power technologies are higher than the ones for fossil fuel power plants, as pointed previously in Table 2.

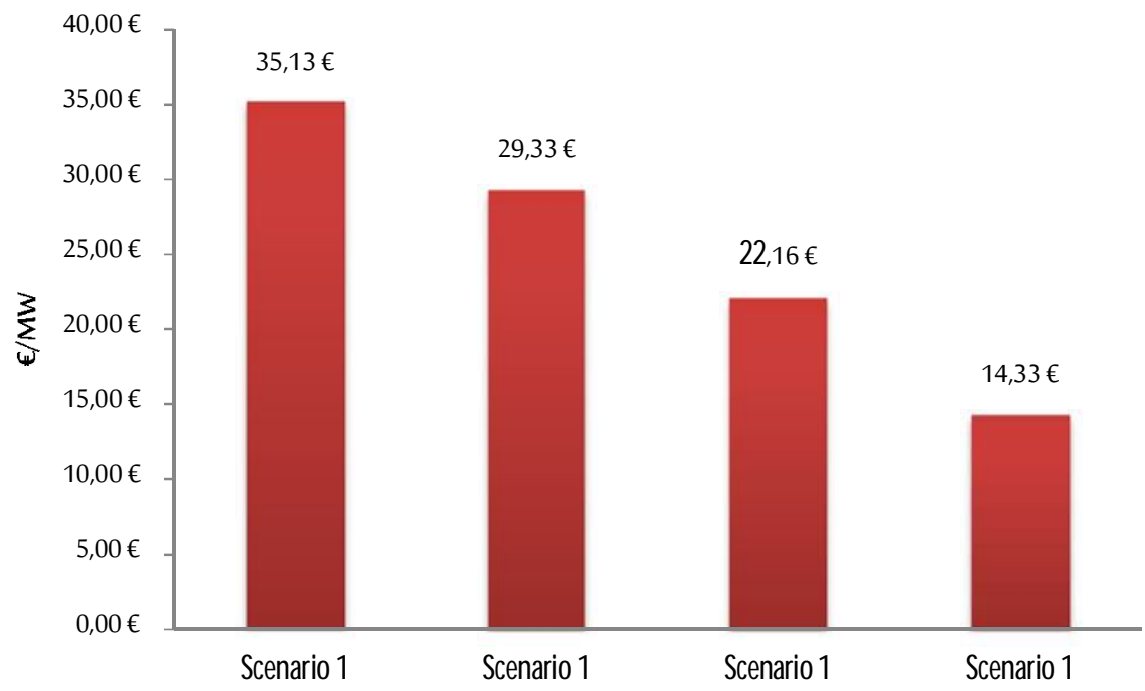

Figure $7 \mathrm{M}$ arginal costs for the four scenarios under analysis

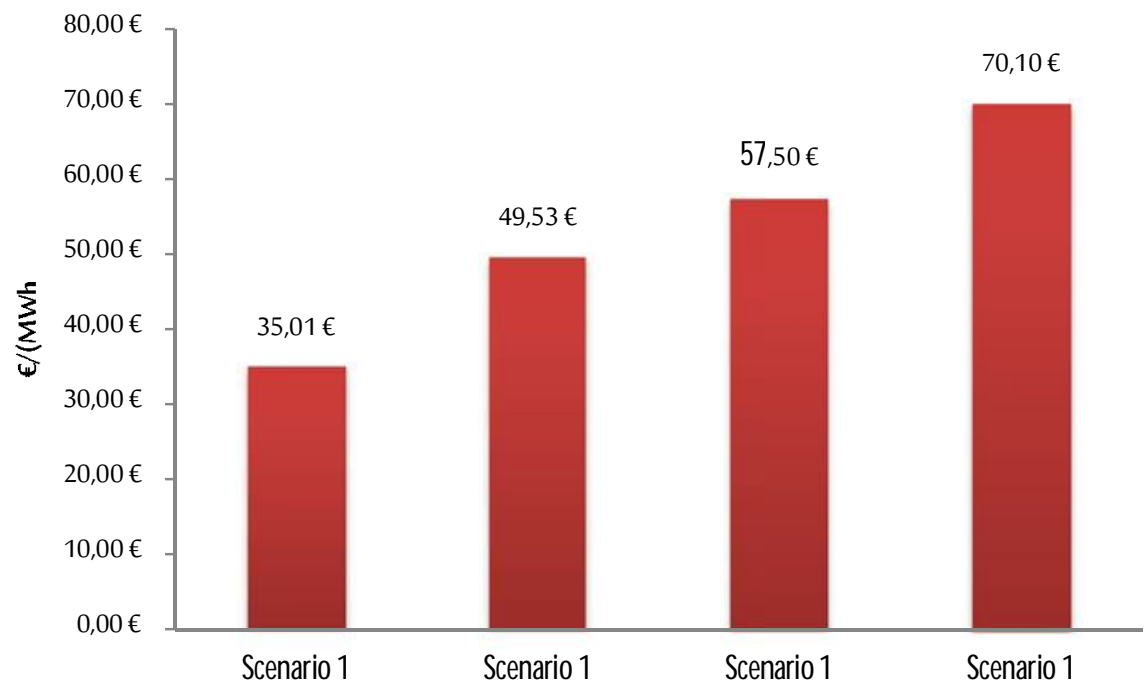

Figure 8 Average cost for the four scenarios under analysis 


\section{Conclusions}

Nowadays, a new world order is emerging regarding energy use and consumption. In this sense, there is a pending need that all countries become self-sufficient regarding production and consumption of energy. By integrating renewable energies in their systems, there will be a considerable reduction of the energy dependency. Over the past years, there has been a description of the goals to achieve framed by national and international legislation, basically setting on renewable energies, where the electricity market stands as the main representative of the energy quotes. Portugal, however, presents itself as a country significantly dependent on energy importations, strongly relying on fossil fuels. Nevertheless, Portugal has a high potential for the development of renewable energies; thus, the Portuguese Government has defined strategic Action Plans, working as orientation and application tools, with the broad aim of achieving $31 \%$ of energy coming from renewable sources in the final gross energy consumption. The integration of these renewable energy sources in the market has been developed by taking advantage of all the existing resources and financial support, whether at a small or large scale aiming at obtaining the most suitable economic, social and environmental practices.

This work aims to contribute to the design of scenarios which include the use of renewable energy sources in Portugal, resourcing to EnergyPLAN model to undertake the simulations. The results obtained in the technical optimization for $100 \%$ RES scenario allowed to conclude achieving a $100 \%$ RES electricity system possible and could guarantee the expected consumption need, however it would generate a significant surplus of electricity translated into exportation surplus.

It was also possible to observe that electricity coming from renewable sources, such as wind and hydro power present the highest figures in all the analyzed scenarios. However, it must be mentioned that both in the PNAER foreseen scenario and in the REN foreseen scenario, a relevant contribution from photovoltaic energy, biomass and waves is included.

Concerning to the EnergyPLAN software, it enabled to obtain specific results on the importation and exportation, identifying as a critical factor the production surplus of electricity throughout the year. This factor justifies the need to introduce, in every scenario, a fixed value for importing/exporting energy, as well as a capacity to interconnect with the outside to ensure balance between supply and demand for the technical optimization. The results put in evidence the need to further explore the economic optimization of the EnergyPLAN model taking into account the hourly electricity costs and also the need to include electricity storage systems as essential elements of $100 \%$ RES systems.

The brief economic analysis conducted in this study focused in the calculation of the costs regarding the implementation of each one of the foreseen scenarios. More specifically, this analysis has mainly addressed the investment costs, the operational and management costs, and the costs with fuel and with the $\mathrm{CO}_{2}$ emissions. It is possible to visualize that the scenarios with higher implementation of renewable energies are those which present higher investment costs, 
tough having the lower marginal costs. In the current Portuguese economic panorama, the investment costs associated with RES can in fact become a barrier for the implementation of $100 \%$ renewable scenarios. However, the obtained marginal costs should also be considered, demonstrating the long term gains of these technologies.

\section{Acknowledgements}

This work was financed by: the QREN - Operational Programme for Competitiveness Factors, the European Union - European Regional Development Fund and National Funds- Portuguese Foundation for Science and Technology, under Project FCOMP-01-0124-FEDER-011377 and Project Pest-OE/EM E/UI0252/2011. 


\section{References}

Connolly, D., et al. (2011) "The first step towards a 100\% renewable energy-system for Ireland" Applied Energy, Vol 88(2), pp. 502-507.

Cósic, B., et al. (2011 a) "A 100\% renewable energy system in the year 2050: the case of south East Europe Energy Community" Dubrovnik Conference on Sustainable Development of Energy, Water and Environment Systems, Dubrovnik, 2011.

Cósic, B., et al. (2011 b) "Towards 100\% renewable energy system: the case of Macedonia", Proceedings of 6th Dubrovnik Conference on Sustainable Development of Energy, Water and Environment Systems.

DGEG (2012) “Renováveis - estatísticas rápidas”, Abril de 2012, o 86.

DGEG e Governo de Portugal - Ministério da Economia e do Emprego (2012) "Linhas estratégicas para a revisão dos Planos Nacionais de Ação para as Energias Renováveis e Eficiência Energética - Versão para Discussão Pública", Lisboa Junho de 2012.

Fernandes, L. (2012) "Um sistema elétrico 100\% renovável na geração de eletricidade - o caso português", Dissertação de M estrado em Gestão Ambiental, Universidade do Minho (In portuguese).

Krajačić, G., et al. (2011) “How to achieve a 100\% RES electricity supply for Portugal?” Applied Energy, Vol. 88 (2), pp. 508-517.

Lund, H. (2011) "EnergyPlan-Advanced Energy Systems Analysis Computer M odel, Documentation Version 9.0", Aalborg University Denmark.

Mathiesen, B.V., et al. (2011) "100\% Renewable energy systems, climate mitigation and economic growth" Applied Energy, Vol 88(2), pp. 488-501.

REN (2011) “Dados Técnicos 2011”.

REN (2011) "PDIRT - Plano de Desenvolvimento e Investimento da Rede de Transportes de Eletricidade 2012-2017 (2022)", Julho de 2011. 